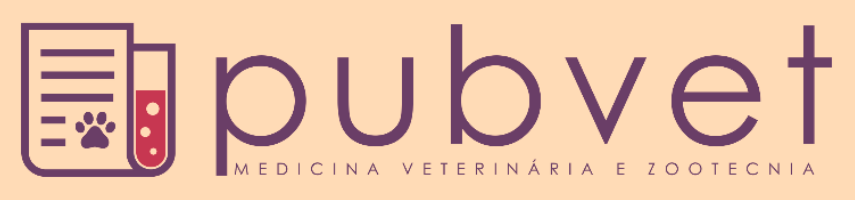

https://doi.org/10.31533/pubvet.v13n1a254.1-4

\title{
Prevalência e perdas econômicas por fasciolose em bovinos abatidos sob regime de inspeção municipal em Itaperuna, Rio de Janeiro
}

\author{
Helen da Costa Rodrigues ${ }^{1 *} \&$ Hingrid Barbosa de Souza ${ }^{\bullet} 2$ \\ I*Discente na Universidade Iguaçu - campus V, Departamento de Medicina Veterinária. Itaperuna-rj, Brasil. E-mail: rodrigueshelen@ @otmail.com \\ ${ }^{2}$ Médica Veterinária na Universidade Iguaçu - campus V, Departamento de Medicina Veterinária. Itaperuna-rj, Brasil. E-mail: hingrid bs@hotmail.com
}

Resumo. A fasciolose hepática conhecida como "baratinha do fígado" é uma enfermidade considerada zoonótica, é causada pelo helminto Fascíola hepática. Existem os hospedeiros definitivos que são os ovinos e bovinos, o parasita infecta o fígado do bovino, e também os hospedeiros intermediários que são os caramujos lymnaea, eles se abrigam em pastos úmidos e açudes. Os fígados infectados são condenados pelo serviço de inspeção nos frigoríficos, pois são considerados impróprios para o consumo humano, sendo assim acarreta em grandes prejuízos econômicos para as indústrias frigorificas. No município de Itaperuna do estado do Rio de Janeiro, foco deste estudo, existe uma elevada prevalência dessa doença. A taxa média da ocorrência da Fascíola hepática em bovinos abatidos no município no mês de janeiro de 2017 à abril de 2018 foi de 15,4\%. Neste cenário, o objetivo deste trabalho foi analisar e informar os índices de condenação de fígados de bovinos devido a fasciolose hepática em frigorifico sob serviço de inspeção municipal localizado em Itaperuna-RJ e mensurar as perdas econômicas causada por essa parasitose. Com resultado de um período de 14 meses obteve um prejuízo de $\mathrm{R} \$ 4.480,00$. Ressaltando à importância da divulgação desses dados para conscientizar os produtores sobre a prevenção dessa doença endêmica em nossa região, como por exemplo a vermifugação dos animais e o manejo adequado do pastejo.

Palavras chave: bovino, caramujo lymnea, fasciolose hepática, zoonose

\section{Prevalence and economic losses due to fasciolosis in cattle slaughtered under a municipal inspection regime in Itaperuna, Rio de Janeiro}

\begin{abstract}
Liver disease known as "liver cheap" is a zoonotic disease, it is caused by the helminth fasciola hepatica. There are definitive hosts that are bovine, the parasite infects the liver of the bovine, and also the intermediate hosts that are lymnea snails, they shelter themselves in humid grazing and dams. Infected livers are condemned by the inspection service in the slaughterhouses, as they are considered unfit for human consumption, and thus entail great economic losses for the refrigerating industries. In the municipality of Itaperuna in the state of Rio de Janeiro, the focus of this study, there is a high prevalence of this disease. The average rate of occurrence of hepatic Fasciola in cattle slaughtered in the municipality from January 2017 to April 2018 was 15.4\%. In this scenario, the objective of this study was to analyze and report the rates of condemnation of bovine livers due to hepatic fasciolosis in a refrigerator under municipal inspection service located in Itaperuna-RJ and to measure the economic losses caused by this parasite. With a result of a period of 14 months it obtained a loss of R $\$ 4,480.00$. Emphasizing the importance of the dissemination of these data to raise awareness among producers about the prevention of this endemic disease in our region, such as deworming of animals and proper management of grazing.
\end{abstract}

Keywords: bovine, lymphatic snail, hepatic fasciolosis, zoonosis 


\title{
Prevalencia y pérdidas económicas por fascioliasis en bovinos sacrificados bajo régimen de inspección municipal en Itaperuna, Rio de Janeiro
}

\begin{abstract}
Resumen. La fascioliasis hepática conocida como "duela del hígado" es una enfermedad considerada zoonótica, es causada por el helminto Fascíola hepática. Existen los hospedadores definitivos que son los ovinos y bovinos, el parásito afecta el hígado del bovino, y también los hospedadores intermediarios que son los caracoles lymnea, se refugian en pastajes húmedos y azudes. Los hígados infectados son condenados por el servicio de inspección en las plantas de sacrificio, pues son considerados inapropiados para el consumo humano, por lo que conlleva a grandes pérdidas económicas para las industrias frigoríficas. En el municipio de Itaperuna del estado de Río de Janeiro, foco de este estudio, existe una elevada prevalencia de esa enfermedad. La tasa media de incidencia de la Fascíola hepática en bovinos abatidos en el municipio durante enero de 2017 a abril de 2018 fue del 15,4\%. Frente a esta situación, el objetivo de este trabajo fue analizar e informar los índices de condena de hígados de bovinos debido a la fascioliasis hepática en plantas de sacrificio bajo servicio de inspección municipal ubicada en Itaperuna-RJ y medir las pérdidas económicas causadas por esta parasitosis. Con el resultado de un período de 14 meses se obtuvo un perjuicio de $\mathrm{R} \$ 4.480,00$. Resaltando la importancia de la divulgación de estos datos para concientizar a los productores sobre la prevención de esta enfermedad endémica en nuestra región, como por ejemplo la vermifugación de los animales y el manejo adecuado del pastoreo.
\end{abstract}

Palabras clave: bovino, caramujo lymnea, fascioliasis hepática, zoonosis

\section{Introdução}

O município de Itaperuna está localizado na mesorregião do Noroeste Fluminense, no estado do Rio de Janeiro, com uma área total de $1.105,341 \mathrm{~km}^{2}$, é atualmente considerado o segundo município do estado do Rio de Janeiro em tamanho de rebanho, com aproximadamente 127.631 cabeças de bovinos, segundo informações do Instituto Brasileiro de Geografia e Estatística - IBGE (2016). Além disto, Itaperuna é centro da cadeia de produção de carne da Região Noroeste Fluminense, possuindo 3 frigoríficos de abate de bovinos.

As doenças parasitárias causam sérios prejuízos na produção pecuária e ocasiona perdas tanto para o produtor rural quanto para a cadeia frigorifica. Quando os bovinos contaminados por faciolose são abatidos em matadouros frigoríficos, os fígados destes animais são considerados impróprios para o consumo humano e condenados, devido esta circunstância gera prejuízo para as indústrias frigoríficas (Rosa, 2016). A faciolose hepática é uma parasitose endêmica no estado do Rio de Janeiro tendo as regiões Norte e Noroeste como as principais regiões de ocorrência no estado. O parasita Fascíola hepática, é pertencente a classe Trematoda e apresenta em humanos um risco relevante à saúde, sendo uma zoonose. O homem é visto como um hospedeiro acidental, sendo fundamental alguns elementos para acontecer a contaminação, tal como a presença do caramujo do gênero Lymnaea (hospedeiro intermediário), umidade e elevada e precipitação. Os números de casos humanos identificados em diversos países tem sido gradativo nas últimas décadas (Oliveira \& Resende, 2017; Pinheiro et al., 2017).

$\mathrm{Na}$ medicina veterinária a fasciolose apresenta elevada relevância, principalmente por causa das perdas econômicas, não só devido à condenação de grande número de fígados e carcaças de animais nos matadouros, mas também por causar queda na produção e na qualidade do leite, perda de peso dos animais, queda na fertilidade, atraso no crescimento, e, ocasionando em alguns casos até mortalidade. Relativamente o potencial de disseminação dessa enfermidade parasitária no mundo, verifica-se uma ampla distribuição vinculada a dispersão no ambiente de espécies de moluscos capazes de albergar estágios larvais do parasito na condição de hospedeiro intermediário (Silva et al., 2008). Sendo um problema de saúde pública por apresentar distribuição global e infecta tanto os humanos quanto os animais. É de fundamental importância entender as características regionais do local estudado e os aspectos relacionados ao parasita para prevenir o aparecimento da doença e saber como controlá-la (Fruet et al., 2013). 
O objetivo do presente trabalho foi realizar um levantamento de dados do número de fígados descartados por faciolose em abatedouro sob o serviço de inspeção municipal da cidade de Itaperuna$\mathrm{RJ}$ e estimar as perdas econômicas ocasionadas pelo descarte de fígados condenados pela doença.

\section{Material e métodos}

O trabalho foi realizado dos dados obtidos no serviço de inspeção municipal de Itaperuna-RJ, mediante a consulta dos relatórios de entradas, dos mapas de condenação de bovinos e manuscritos do livro de registro oficial do frigorífico, contendo informações como a duração do abate, número de animais abatidos, número dos Guia de Trânsito Animal (GTA) e condenação. O período analisado foi de 14 meses.

Os dados foram digitalizados em planilhas para a realização do levantamento e posterior cálculo da prevalência da doença, tendo o total de 1.457 bovinos abatidos em um frigorifico do município. Foi construído um gráfico ilustrando a ocorrência mensal dos casos de fasciolose.

\section{Resultados e discussão}

Foram analisados dados de 14 meses referentes aos anos de 2017 e 2018, de condenação por fasciolose. No total de 1.457 bovinos abatidos no frigorifico, 224 fígados foram condenados por fasciolose, resultando em uma prevalência de $15,4 \%$. Considerando que um fígado pesa em média de 4 $\mathrm{kg}$ e que o preço atualmente está $\mathrm{R} \$ 5,00$ por quilo, pode mensurar que em 14 meses as perdas resultantes da fasciolose giram em torno de $\mathrm{R} \$ 4.480,00$, no qual este valor refere-se apenas às perdas causadas pelo descarte dos fígados, não está incluindo a diminuição do ganho de peso, queda das taxas de fertilidade, atraso no crescimento e morte.

No gráfico abaixo podem ser observados os dados de condenação com números de animais abatidos no frigorífico e condenação de fígados por fascíola. Durante janeiro de 2017 a abril de 2018. Nos dados que foram coletados não havia informação referente ao mês de fevereiro de 2018.

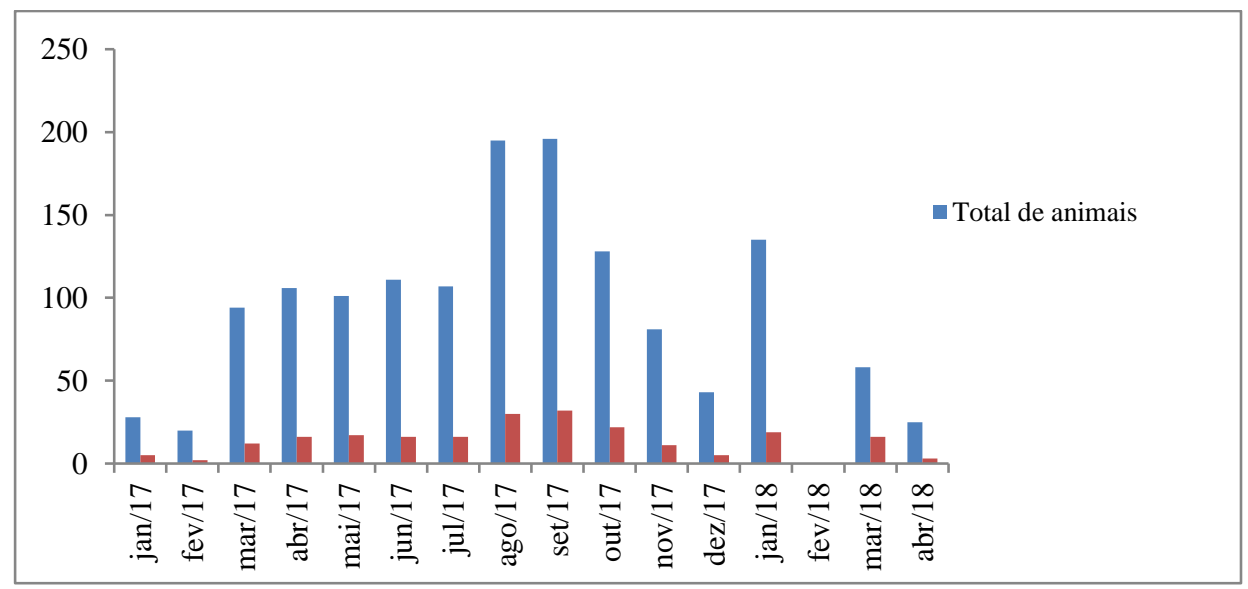

Gráfico 1. Representação do número de fígados condenados por fasciolose hepática no Frigorífico durante os anos de 2017 e 2018. Itaperuna, RJ, 2018.

Como foi observado no gráfico 1 , mês que mais teve prevalência por fasciolose hepática em bovinos foi o mês de setembro de 2017 com 16,4\% de condenações dos fígados. E o menor mês de prevalência, onde ocorreu $10 \%$ de condenação foi o mês de fevereiro. Todavia, esses índices de maior e menor prevalência nesses meses podem ser justificados por um número de abate. Na pesquisa realizada por Oliveira (2008) descreve que a população decrescia ciclicamente entre os meses de setembro e janeiro, e aumentava entre março e setembro. A comparação entre o tamanho dos caramujos sugeriu que pode haver duas gerações de L. columella por ano. A prevalência da infeção em L. columella oscilou, durante os dois anos de estudo entre, $8,8 \%$ e 17,9\%. Este resultado associado com a taxa de infecção dos animais traçadores sugeriu um maior número de metacercárias nas pastagens entre os meses de junho e outubro e março e abril, mas a infeção permaneceu presente durante todo ao ano. 
Oliveira (2008) observou no município Careaçú no estado de Minas Gerais, que das 158 amostras examinadas, foram assinalados 23 exames positivos, com uma taxa de prevalência de fígados condenados por fasciolose hepática, obtendo o resultado de 14,5\%. Sendo assim, as porcentagens ficam bem próximas às do município de Itaperuna-RJ, que foram de 16,4\%. De acordo com Rosa (2016), no Rio Grande do Sul obteve os resultados que demonstram a presença de Fasciola hepática em 13,8\% dos animais abatidos durante o período em que foi estudado.

Tem sido cada vez mais difícil o controle dessa parasitose devido à necessidade de estabelecer um mecanismo de controle integrado, procedendo desde o hospedeiro definitivo até o hospedeiro intermediário e o meio ambiente (Oliveira \& Resende, 2017; Oliveira, 2008; Sanchez-Vazquez \& Lewis, 2013). Sendo assim, fica bem claro a importância de um elevado controle sanitário dos animais pertencentes a regiões propícias a proliferações do caramujo e a manifestação com a presença da Fasciola hepática. Por isso, técnicas de controle de sanidade animal e maior fiscalização são essenciais para evitar a ocorrência de novos casos (Oliveira, 2008).

\section{Conclusão}

De acordo com os dados obtidos no presente trabalho no período de 14 meses, conclui que o município d Itaperuna, Rio de Janeiro é considerado uma cidade endêmica por fasciolose hepática em bovinos. Além de ser uma zoonose, tendo importância na medicina veterinária, essa enfermidade também gera grandes prejuízos econômicos, tanto para o ciclo de vida do animal, quanto para os frigoríficos. Sendo importante também para a saúde pública, para alertar e tomar medidas de prevenção em casos humanos da doença futuramente.

\section{Referências bibliográficas}

Fruet, A. P. B., Fabrício, E. A., Kirinus, J. K., Scortegagna, A., Dörr, A. C. \& Nörnberg, J. L. (2013). Perdas econômicas oriundas das condenações de vísceras bovinas em matadouros de Santa Maria, Rio Grande do Sul. Revista Brasileira de Ciência Veterinária, 20(2), 99-103.

IBGE, Produção da Pecuária Municipal 2016. Rio de Janeiro: IBGE, 2016. Disponível em file:///C:/Users/hingrid/Desktop/fasciola/IBGE\%20\%20\%20Cidades\%20\%20\%20Rio\%20de\%2 0Janeir o\%20\%20\%20Itaperuna\%20\%20\%20Pecu\%E1ria\%20-\%202013.html. Acesso em 14/05/18.

Oliveira, D. M. \& Resende, P. O. (2017). Fasciola hepatica: ecologia e trajetória histórico-geográfica pelo Brasil. Estação Científica (UNIFAP), 7(2), 9-19.

Oliveira, E. L. (2008). Prevalência e fatores associados à distribuição da Fasciola hepatica Linnaeus, 1758 em bovinos dos municípios de Careacú e Itajubá, região da Bacia do Rio Sapucaí, Minas Gerais. Instituto de Ciências Biológicas, 4(6), 1-101.

Pinheiro, E. O. P., Silva, F. F. A. V., Pinheiro, L. S., Feitosa, T. K. A., Florêncio, T. A. \& Prado, R. M. S. (2017). Fascíola hepática: o parasita acidental do homem. Mostra Científica da Farmácia, Qixadá, 2(4), 1-4.

Rosa, M. C. (2016). Prevalência de fasciolose em bovinos abatidos sob regime de inspeção federal no Estado do Rio Grande do Sul. Repositório Digital, 7(9), 1-29.

Sanchez-Vazquez, M. J. \& Lewis, F. I. (2013). Investigating the impact of fasciolosis on cattle carcase performance. Veterinary Parasitology, 193(1-3), 307-311. doi: http://dx.doi.org/10.1016/j.vetpar.2012.11.030

Silva, E. R. V., Capoani, R. Q., Ritz, R., Surian, C. R. d. S. \& Neves, M. F. (2008). Fasciolose hepática. Revista Científica Eletrônica de Medicina Veterinária, 6(11), 1-7.

Recebido: 1 dezembro, 2018.

Aprovado: 23 dezembro, 2018.

Publicado: 22 janeiro, 2019.

Licenciamento: Este artigo é publicado na modalidade Acesso Aberto sob a licença Creative Commons Atribuição 4.0 (CC-BY 4.0), a qual permite uso irrestrito, distribuição, reprodução em qualquer meio, desde que o autor e a fonte sejam devidamente creditados. 